\title{
Glorious past, uncertain present, bad future? Assessing effects of land-use changes on habitat suitability for a threatened farmland bird species
}

\author{
Mattia Brambilla $^{\mathrm{a}, *}$, Fabio Casale ${ }^{\mathrm{a}, \mathrm{b}}$, Valentina Bergero ${ }^{\mathrm{a}}$, Giuseppe Bogliani ${ }^{\mathrm{c}}$, G. Matteo Crovetto $^{\mathrm{a}, \mathrm{d}}$, \\ Riccardo Falco ${ }^{\mathrm{a}}$, Michaela Roati ${ }^{\mathrm{e}}$, Irene Negri ${ }^{\mathrm{c}}$ \\ a Fondazione Lombardia per l'Ambiente, Settore Biodiversità e Aree protette, Piazza Diaz 7, I-20123 Milano, Italy \\ ${ }^{\mathrm{b}}$ Università degli Studi dell'Insubria, Dipartimento Ambiente-Salute-Sicurezza, Via Dunant 3, I-21100 Varese, Italy \\ ${ }^{\mathrm{c}}$ Università degli Studi di Pavia, Dipartimento di Biologia Animale, Via Adolfo Ferrata 1, I-27100 Pavia, Italy \\ d Università degli Studi di Milano, Dipartimento di Scienze Animali, Via Celoria 2, I-20133 Milano, Italy \\ e Università degli Studi di Pavia, Dipartimento di Ecologia del Territorio, Via Sant'Epifanio 14, I-27100 Pavia, Italy
}

\section{A R T I C L E I N F O}

\section{Article history:}

Received 4 March 2010

Received in revised form 3 July 2010

Accepted 19 July 2010

Available online 12 August 2010

\section{Keywords:}

Dynamic scenarios

Farming

Habitat suitability models

Land abandonment

Land-use changes

Lanius collurio

\begin{abstract}
A B S T R A C T
Land-use changes have strong impacts on biological communities. Among them, land abandonment is threatening a large number of conservation-concern species associated with semi-natural habitats shaped by 'traditional' farming. We focused on the red-backed shrike as a model for investigating the effect of land abandonment on a threatened bird species, and used historical data to model dynamic scenarios. We explored variations in habitat suitability from the 1950s to the present and predicted possible future variations. After investigating local habitat preferences of the species, we formulated a spatially explicit model of habitat suitability for shrikes according to current land-use types; then, we evaluated past habitat suitability, by applying the model to three known past scenarios, and simulated the habitat changes after land abandonment. By combining a habitat-association approach with past and future land use scenarios, we assessed and predicted the effects of habitat changes caused by abandonment. Shrike occurrence was favoured by the cover of four types of grassland and of shrubland with trees, and negatively affected by broadleaved woodlands. The current average habitat suitability is less than half of what it was in the 1950s. Future predictions in a complete abandonment scenario suggest that important decrease could be expected 10 or 20 years after abandonment, and that after 30 years the red-backed shrike would be completely extinct. Alternative scenarios involving partial abandonment suggested that subsidy policies may mitigate the effects of abandonment. Knowing land-use dynamics allowed the exploration of effects of land-use changes and corroborated the importance of low-intensity farming for conservation.
\end{abstract}

(c) 2010 Elsevier Ltd. All rights reserved.

\section{Introduction}

Changes in land-use have a global effect (Leemans and Zuidema, 1995; Hurtt et al., 2006) and, interacting with other components of global change, have a strong impact on the structure of biological communities (Sala et al., 2000; Thomas et al., 2004; Rosenzweig et al., 2008; Gil-Tena et al., 2009). Mediterranean ecosystems appear to be especially susceptible to the impacts of global change (Lavorel et al., 1998), because of the high exposure to human activities (Blondel, 2006), the sensitivity to climatic conditions (Peñuelas et al., 2002) and the simultaneous impact of several factors (Sala et al., 2000). The effects on biodiversity of such impacts are largely unknown (Sala et al., 2000), may be non-linear and may display opposite directions (Gil-Tena et al., 2009).

\footnotetext{
* Corresponding author. Tel.: +39 0280616140; fax: +39 0280616180

E-mail address: brambilla.mattia@gmail.com (M. Brambilla).
}

Land abandonment has been an important land-use change in recent decades, being a major consequence of socio-economic changes in highly industrialized countries (Ostermann, 1998). The decrease in farming primarily affects the least productive agricultural land and triggers a recovery of semi-natural vegetation (Sirami et al., 2008). In most of the Mediterranean region, land abandonment has occurred during the last century. This has led to the naturalization and vegetation closure of many areas, thus favouring the spread of forests (e.g. Debussche et al., 1999; Poyatos et al., 2003; Roura-Pascual et al., 2005). The Northern Mediterranean basin has a long-term and complex history of human exploitation, which has largely shaped its landscapes and associated fauna (Blondel, 2006). It has recently experienced fast and widespread agricultural abandonment (Mazzoleni et al., 2004), which appears to be an important cause of species declines, especially in bird communities (Farina, 1995, 1997). The recovery of seminatural vegetation that results from agricultural abandonment 
causes a decrease of open grassland-like habitats and an increase in shrubland and, especially on the long-term, woodland cover (Debussche et al., 1999; Romero-Calcerrada and Perry, 2004). This causes a decline of species tied to open habitats (Preiss et al., 1997; Suárez-Seoane et al., 2002; Sirami et al., 2007), with migrant species associated with open farmland habitats being particularly affected (Sirami et al., 2008). In general, many species of conservation concern in Europe are associated with traditional farm landscapes and the semi-natural habitats they produce and maintain (see e.g. Tucker and Evans, 1997). Such types of landscapes have been increasingly studied in order to understand mechanisms underlying the decline of farmland birds (Benton et al., 2003) and the main steps to be taken for their conservation (Donald et al., 2002).

On the basis of the above, assessments are urgently required on the impact (past, current, and likely future) of environmental change, on animal communities and especially on threatened bird species in the Mediterranean region. Assessments should especially include land abandonment and the consequential fast recovery of forest, further boosted by climate change and frequency of fires (Grigulis et al., 2005).

However, as it is rare to have enough information on past landuses: (i) it is difficult to assess previous ecological gain or loss, and (ii) future predictions are often built up without a historical base. Although notable exceptions exist (see e.g. Domenech et al., 2005; Ficetola et al., 2009; Fouquet et al., 2010), none of them consider farmland birds, one of the main concerns for conservationists at the beginning of the third millennium.

Among depleted and declining farmland birds, the red-backed shrike Lanius collurio is a typical inhabitant of semi-open habitats created and maintained by 'traditional', low-intensity agricultural practices (Fornasari et al., 1997). A recent study revealed that shrike conservation in southern European farmed landscapes depends on a trade-off between 'intense' agricultural land use and 'partial' land abandonment, which provide complementary resources (Brambilla et al., 2007a). Other research in different European countries has highlighted a similar pattern: red-backed shrikes occupy mostly farmed landscapes characterised by a matrix of fields and grasslands, within which marginal features are interspersed, such as shrubs, hedgerows and small trees (Kuzniak and Tryjanowski, 2000; Vanhinsbergh and Evans, 2002; Karlsson, 2004; Tryjanowski et al., 2007; Golawski and Golawska, 2008; Golawski and Meissner, 2008; Brambilla et al., 2009a). These widely converging findings, coming from different geographical contexts, emphasise how red-backed shrikes are principally tied to an 'intermediate' ecological disturbance created by agropastoral activities over biological communities and environment. Red-backed shrikes need open areas with low grass provided by pastures, mown grasslands or grassy arable-fields; they also need shrubs or small trees for perching and nesting sites, which are found in areas not directly used for agricultural purposes, or by portions of pasture with a lower grazing pressure. Finally, untilled herbaceous plants favour shrike occurrence by positively affecting the abundance and availability of invertebrate prey; untilled grasslands are often ensured by fallow land or set-aside. When a similar mosaic pattern (which in most European countries does not occur as a 'natural' feature but only as a by-product of traditional agricultural land use) is created 'ad hoc' by habitat management, shrikes respond positively to this improved habitat quality with a steady population increase, stressing the link between this species and the habitat mosaic created by low-intensity agriculture (Casale et al., 2007, and references therein).

Red-backed shrikes are quite easy to note and locate, thanks to their conspicuous behaviour, and previous spatially explicit models of habitat suitability for this species, based on land use features, lead to valid predictions of species abundance (Brambilla et al., 2009a). The red-backed shrike in the northern Mediterranean basin thus appears to be an ideal model for investigating the effect of habitat changes, caused by land abandonment, on threatened farmland birds.

With this work we model habitat suitability for the study species according to dynamic land-use contexts. We analyse the species' habitat requirements in a landscape widely shaped by traditional agricultural use, where historical changes in land use and associated vegetation structure are known; then, we explore variations in habitat suitability from the 1950 s to the present and predict future habitat suitability in a land-abandonment scenario.

The simultaneous occurrence of a range of neighbouring landtypes allows us to investigate how strictly red-backed shrikes are dependent on different types of land use. Such types include land for non-intensive crop production and livestock grazing as well as arable-fields, pastures and woodland that have been abandoned recently or in the past. We formulate a spatially explicit model of habitat suitability for the species according to the current pattern of land-use types. Then we evaluate past habitat suitability, by applying our model to three known past scenarios (dating back to the 1950s), and simulate the development of vegetation communities after complete land abandonment, i.e. the cessation of all agricultural and pastoral activities. We simulate the progressive substitution of fields and pastures by shrubland and tree communities, setting the time and order of habitat succession on the basis of the historical evidence of land-use changes. By estimating past habitat suitability and by simulating the future evolution of landuse cover in an abandonment scenario (quite likely to occur in future decades), we further test the effect of land abandonment on shrike occurrence. Land abandonment has been the major force driving landscape changes in recent years in the study area (Bogliani et al., 2003; see also Fig. 1) and in other mountainous regions.

The analysis of possible future scenarios, calibrated using historical data, allowed us to predict the effects of land abandonment on this declining species. Red-backed shrike could also be used as a model for entire biological communities of low-intensity agricultural areas, at least in northern Italy, where it is an indicator of high biodiversity (Brambilla et al., 2009a; Casale and Brambilla, 2009). Since land-use changes (like the ones we consider here), represent a common phenomenon in most of southern European and Mediterranean mountainous areas, we believe that our study species/ case may have a more general interest, and may often be applicable

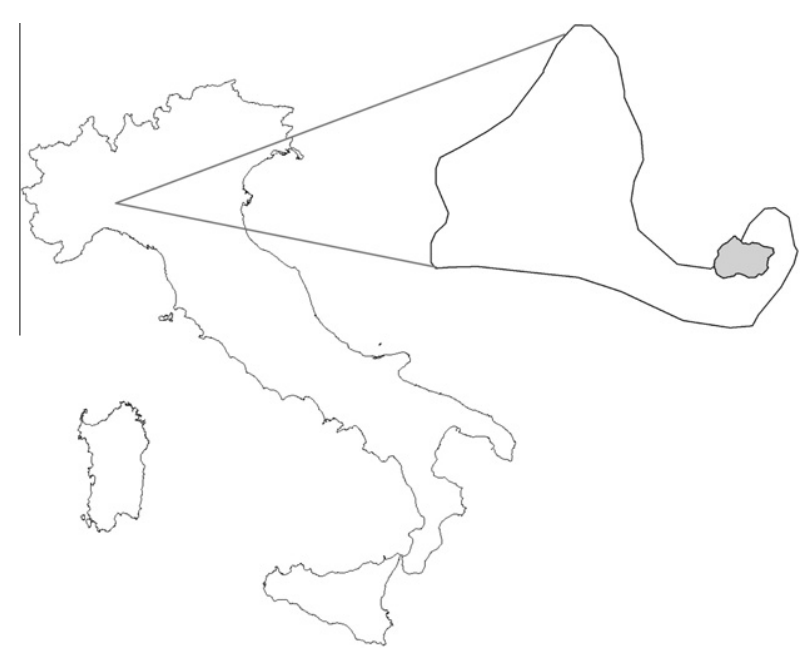

Fig. 1. Location in Italy of our study area in the northern Apennines (white polygon), with the historical plot (grey patch comprised within the study area). 
to the species-rich (and conservation priority) biological communities of traditionally farmed landscapes.

\section{Materials and methods}

\subsection{Study area}

The study area (18,040 ha) is located in the northern Apennines (Italy, Lombardy, province of Pavia, Fig. 1), roughly on the boundary of the Mediterranean and Eurosiberian regions. This area holds a large diversity of farmland birds (Bogliani et al., 2003) and important populations of many conservation-concern species (e.g. Negri et al., 2005; Brambilla et al., 2008, 2009b). The red-backed shrike is the only shrike species regularly breeding in the area; therefore, the potential effects of the occurrence of other shrike species cannot influence the distribution and habitat selection of our model species (cf. Hromada et al., 2008). The landscape is one of the few non-intensive agricultural systems remaining in central and northern Italy, and is flanked by woodlands (mainly oaks at lower and beeches at higher altitudes) and rocky habitats. Altitude ranges between 169 and $1263 \mathrm{~m}$ a.s.l. (mean $538 \mathrm{~m}$, median $490 \mathrm{~m}$ a.s.l.).

The main habitats are fields (generally smaller than a few hectares), consisting of arable land seeded with cereals and lucerne Medicago sativa, fodder and fallow lands, vineyards, villages and small towns, rocky outcrops, broadleaved woodlands, pine plantations, small rivers, calanques (sandy/rocky mountainsides subjected to erosion), sub-Mediterranean garigues (low and sparse shrubland of dry areas), and areas of recently-abandoned fields and pastures progressively being covered by shrubs and trees. Archaeological and historical evidence suggests that the processes which led to the present landscape structure in the northern Apennines can be described by the following few characteristic stages (Montanari et al., 2002; Moreno et al., 2005): slashing and burning (which transformed forests into cultural landscapes, beginning as early as the Bronze Age; Maggi, 2004); removing stones, levelling the ground and reshaping the original profile (based on archaeological evidence dating back to the Early Middle Ages; Cevasco, 2007); terracing and permanently cultivating (mainly due to the increase in the human population in mountains during the 18th19th Centuries); changing from cultivating to pasturing; finally, frequent abandonment of pastures in the second half of the 20th Century. Agricultural and pastoral activities (which are all nonintensive within the area) are now rapidly decreasing, with a consequential loss of cultivated/grazed areas. For further details on habitat features of that part of the Apennines see Bogliani et al. (2003) and Brambilla et al. (2008, 2009b).

For a subsample of our study area (650 ha), historical data about vegetation structure and land-use changes were available (Fig. 2): the cover of woodland, shrubland and agricultural areas (including seeded and permanent grasslands - the latter with or without scattered shrubs and trees) were quantified and mapped in 1950, 1982 and 2000 , by using detailed aerial photographs. This provided a unique opportunity for evaluating the real trend of vegetation types in a plot representative of the whole study area and the historical changes in habitat suitability for our model species.

\subsection{Fieldwork}

We counted shrikes in 13 plots (average area 88 ha), scattered over the whole study area and chosen as being representative of the different types of semi-open habitats potentially suitable for the species: areas covered mainly by arable-fields, permanent grassland (mown grassland, pasture, grassland with trees and shrubs), large clearings, dry grassland, etc.
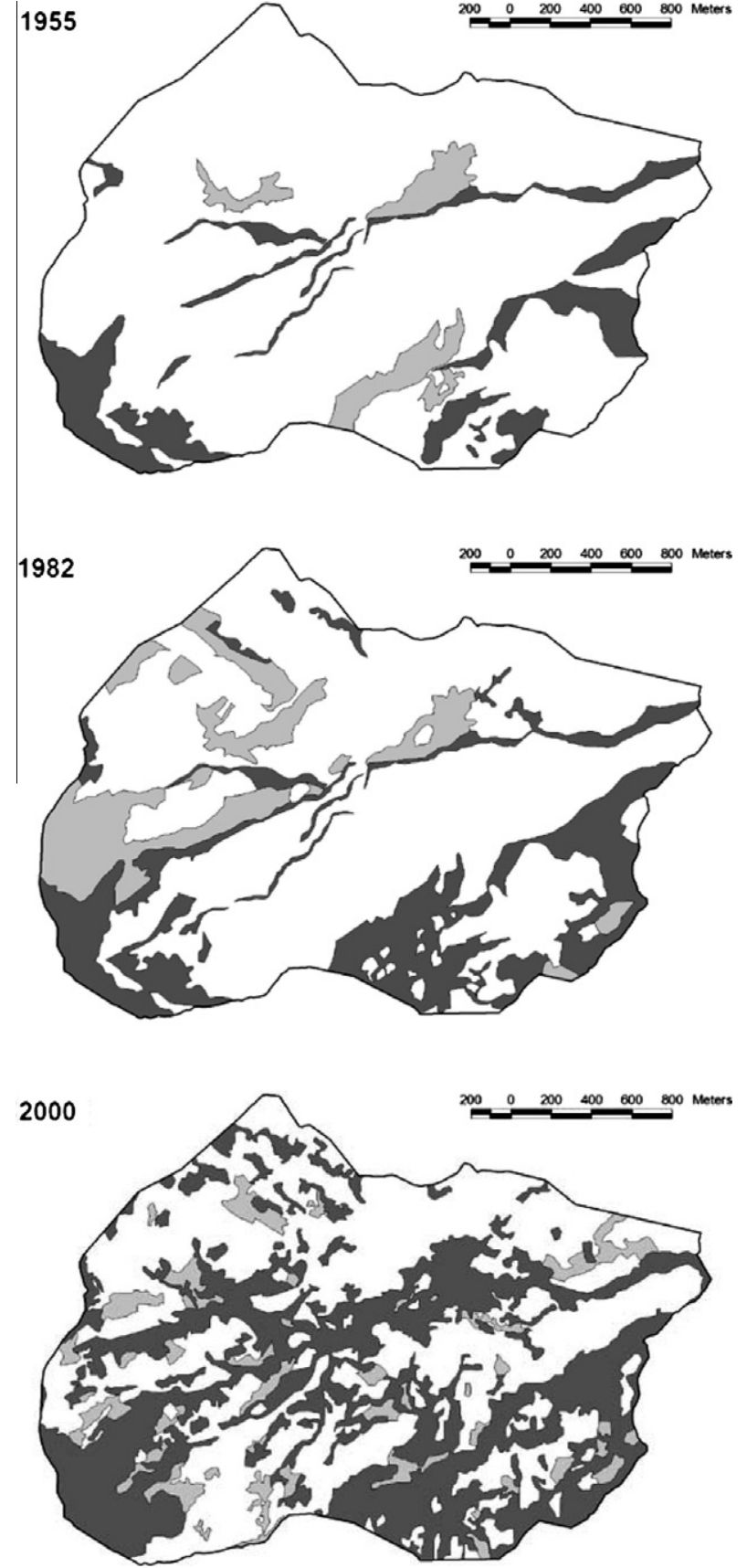

Fig. 2. Changes in land-use cover in the 'historical' study plot: white: agricultural areas (seeded and permanent grasslands, including permanent grasslands with scattered trees and shrubs); pale grey: shrublands; dark grey: woodland. The effects of land abandonment are striking, with a dramatic expansion of woodland over other land uses.

Shrikes were surveyed by territory mapping during June, July and August 2008. The survey period was slightly postponed compared to a previous study in a neighbouring region (Brambilla et al., 2007a), but mirrored our recent work in Lombardy (Brambilla et al., 2009a), because in both 2007 and 2008 migrant birds were noted until 25 May and breeders settled relatively late during the season (Brambilla et al., 2009a; Casale and Brambilla, 2009). Each study plot was surveyed on three to five dates and between 05:00 and 12:00 a.m. All contacts and nests found were recorded on aerial photographs (scale 1:2000). We defined a territory centre as the midpoint of all records obtained from a pair - particularly a male and female together, a singing male, aggressive encounters 
and pairs showing courting, copulating or nesting behaviour. This follows methods used elsewhere with the same species (Brambilla et al., 2007a and references therein). Because of the marked territoriality of this species, these records are useful to define territory shape (Karlsson, 2004; Tryjanowski and Golawski, 2004). Seventyone territories were mapped within the 13 study plots.

\subsection{Habitat association of the red-backed shrike}

Seventy-one random points were generated by means of a GIS procedure over the entire area encompassing the study plots. Territory midpoints and random points were buffered to create 142 circular plots of 1 ha each, by means of GIS. One hectare was thought to be a good approximation of territory size in the Apennines and Lombardy (Brambilla et al., 2007a, 2009a). In each plot we measured the proportional cover of 14 types of land use (Table 1). Habitat cover and hedgerow length were estimated on a highdefinition land-use map (scale 1:10,000; DUSAF2, ERSAF-Regione Lombardia), which finely distinguished between different types of vegetation. Equally, the map distinguished between vegetation types on abandoned land: transitional vegetation, such as recently abandoned areas progressively being covered by shrubs, or shrubland progressively being invaded by trees. These virtually formed a gradient from agro-pastoral land to woodland. Therefore, such a database was particularly useful for the purpose of our study.

Habitat cover variables were arcsine-square-root transformed. We assessed, by means of a logistic regression analysis, the variables likely to affect habitat selection by red-backed shrikes. We adopted an AIC-based approach, carried out in R (stepAIC function); then, a stepwise backward procedure of variable selection was also carried out, either based on the likelihood-ratio test and on the $z$-statistic. In both the AIC-based and stepwise procedures, quadratic terms of the variables included in the model with positive effects were also tested, but they were always non-significant and were not retained in the model.

We calculated the area under the curve of the ROC plot, based on a nonparametric assumption (Pearce and Ferrier, 2000; Gibson et al., 2004; Rushton et al., 2004). In the final model, standardised residuals approached a normal distribution and the data were not overdispersed (Rushton et al., 2004). We also performed a hierarchical partitioning analysis, which provides estimates of the independent and joint explanatory power of predictors, considering all possible models in the regression setting (Chevan and Sutherland, 1991; Mac Nally, 1996, 2000). Variables with large independent values are most likely to be causal (Mac Nally, 2000), and consequently relevant for management (Brambilla and Rubolini, 2005).
The independent contribution of each explanatory variable may be used to check and validate the results of regression analyses (Mac Nally, 2000; Heikkinen et al., 2004; Radford and Bennett, 2004; Brambilla et al., 2006). Because of software limitation (maximum 12 variables), from our set of 15 potential predictors we excluded the three variables that showed the least significant difference between occupied and unoccupied plots in a $t$-test comparison, and that were not included in any possible model, in order to leave out the variables presumably less important. This analysis was performed by means of the 'hier.part' R-package (Walsh and Mac Nally, 2003), using the log-likelihood as goodness-of-fit measure (Mac Nally, 2000). Means and parameter estimates are reported together with their standard errors, unless stated otherwise.

\subsection{Predicting past, current and future habitat suitability}

Maps of habitat suitability were created by integrating individual shrikes' habitat choice with the habitat distribution in the study area, assuming that the spatial distribution of the species results from the collective outcome of the habitat choice of individuals (Sergio et al., 2004; Brambilla et al., 2009a). Although such a modelling procedure cannot take into account the effects of social information/interaction of shrikes, it has been proved to be effective for predicting habitat suitability and distribution of redbacked shrikes in the same region of this study (Brambilla et al., 2009a), and thus is likely to be useful for the scope of our work. Moreover, the quite good discriminatory power suggests that the model is adequate for describing the features of habitat selected by shrikes in the study area (see Section 3). We produced a map of current habitat suitability (based on the 2007 DUSAF2 landuse map) by extrapolating the habitat model to the entire study area, by means of 5000 randomly scattered points which were generated through a GIS procedure and independent of the territories and random plots used for the definition of habitat preferences. At each of the 5000 points we used the estimated probability of species occurrence as an index of habitat suitability (Gibson et al., 2004). For each point, we created a 1 -ha circle, in which the variables included in the model were measured (adopting the same method used for territories and random plots). Then, we applied the logistic regression model to each of the random plots, obtaining the relative occurrence probability. Next, an interpolation procedure (Analysis: Kriging Interpolation, under the extension Spatial Tools 3.4 in ArcView 3.2, ESRI) based on the occurrence probability allowed us to draw a map (resolution: $20 \mathrm{~m}$ ) of habitat suitability for the whole study area.

Table 1

Habitat variables measured in territories and random plots. The proportional cover of habitat variables was arcsin-square-root transformed prior to statistical tests.

\begin{tabular}{ll}
\hline Variable & Description \\
\hline Length of hedgerows & Length of hedgerows (m) within the plot \\
Urban habitats & Cover of urbanized areas \\
Seeded grasslands & Cover of land with herbaceous cultivations, including areas subjected to rotation and fallow land \\
Poplar cultivations & Cover of Populus spp. plantations \\
Other woody cultivations & Cover of other perennial crops \\
Permanent grasslands & Cover of pastures, mown or other grasslands \\
Permanent grasslands with scattered trees and & Cover of pastures, mown or other grasslands with scattered trees and shrubs \\
shrubs & Cover of broadleaved woodlands \\
Broadleaved woodlands & Cover of broadleaved trees at low density \\
Open broadleaved woodlands & Cover of coniferous woodlands \\
Coniferous woodlands & Cover of shrub vegetation with scattered (<10\% of the surface) trees, mainly originated by forest expansion \\
Shrubland with trees & Cover of herbaceous and/or shrubby vegetation over once mown or grazed areas (possible occurrence of trees over \\
Abandoned areas & $<10 \%$ of the surface) \\
Vineyards & Cover of vineyards \\
Orchards & Cover of orchards \\
Sparse vegetation & Cover of low-density vegetation of rocky faces, stony or sandy soils
\end{tabular}


Then, we applied a simplified version of the model (obtained by combining certain land uses because of the limitation in variablesrecording from historical aerial photographs; see Section 3) to past and current scenarios, to assess any changes in habitat suitability that occurred in the 'historical' plot between 1955 and 1982, and since 2000 and 2007. Throughout this analysis, we have estimated variations in habitat suitability, within the 650-ha plot, that have occurred during the past 50 years.

We then tried to assess habitat suitability after land abandonment. For this we used land-use changes that occurred within the 'historical' study plot (Fig. 2), as well as previous studies (Roati, 2007) and other more recent field observations, to develop a simulation of habitat change. We supposed that, after 10 years of land abandonment, arable-fields and permanent grasslands change into "abandoned areas", abandoned areas and permanent grasslands with trees/shrubs change into shrubland with trees, and existing shrubland with trees becomes woodland (Table 2). Although this is necessarily a rough approximation and the relative speed of vegetation succession varies from one land-type to another (depending on vegetation and soil-type), it seemed that a 10 -year period should be a good approximation for each of the three main transitions to occur. This is perfectly parallel to the changes that occurred in the 'historical' study plot (see Fig. 2). Moreover, for our geographical area, Verburg and Overmars (2009) reported an estimated time for the transition from agriculture to semi-natural (shrubland) habitats of less than 12 years, and of less than 15 years for the transition from semi-natural (shrubland) habitats to forest. Therefore, all available evidence supports the supposed phases and speed of habitat succession.

Therefore, we estimated the average shrike-occurrence probability in the abandoned landscapes and drew a habitat suitability map after 10 (2017) and 20 (2027) years from the current situation (2007). We did not produce a habitat suitability map for 2037, because under the estimated speed of habitat succession from open land to forest, there were no suitable sites for red-backed shrikes after 30 years of farming cessation (see Section 3 ).

We also developed two alternative scenarios characterised by partial land abandonment. In the first, seeded grasslands are maintained, while permanent grasslands and permanent grasslands with scattered trees and shrubs are abandoned. In the second, we envisaged the opposite condition, with seeded grasslands abandoned and the other two grassland types maintained. In the case of other habitat types, we assumed the same successionary processes as those considered in the complete abandonment scenario (Table 2). These two alternative scenarios are more or less likely to happen in future depending on the nature and economical benefits of subsidies made available to farmers.

\section{Results}

\subsection{Habitat association}

The AIC-based model selection and the two stepwise backward procedures provided nearly identical results, with all three meth- ods leading to the same model. The only exception was for permanent grassland, which resulted marginally significant in stepwise procedures ( $P \sim 0.1$ under both approaches) and which was therefore left out from those models at the last step. However, the model including permanent grasslands seemed to be more meaningful, as many of the cultivated fields within shrikes' territories were managed as fallow land for hay-making or occasional grazing. Therefore, there was a substantial consistency between the results of the information-criteria approach and the stepwise procedures.

The habitat model (each variable reported with the change in 2LogLikelihood associated with variable removal from the model) included (intercept: $\beta=-3.36 \pm 1.18$ ) seeded grassland $(\beta=$ $\left.3.13 \pm 0.86 ; \quad \chi^{2}=17.56 ; \quad P<0.001\right)$, abandoned areas $(\beta=$ $\left.2.92 \pm 1.02 ; \chi^{2}=9.86 ; P=0.002\right)$, shrubland with trees $(\beta=3.43 \pm$ $\left.1.39 ; \chi^{2}=6.91 ; P=0.009\right)$, permanent grasslands $(\beta=2.22 \pm 1.38$; $\left.\chi^{2}=2.53 ; P=0.112\right)$, broadleaved woodlands $(\beta=-2.52 \pm 1.27$; $\left.\chi^{2}=4.54 ; P=0.033\right)$, permanent grasslands with scattered trees and shrubs $\left(\beta=3.82 \pm 1.11 ; \chi^{2}=17.40 ; P<0.001\right)$. The AUC of the ROC plot for the model was equal to $0.89 \pm 0.03$.

Hierarchical partitioning provided strong support for the habitat association model we obtained: the most relevant variables (accounting together for nearly $75 \%$ of the overall independent explanatory power) were broadleaved woodland, seeded grasslands and permanent grasslands with scattered trees and shrubs; all other variables had relative independent explanatory power between $1.9 \%$ and $5.6 \%$.

\subsection{Current, past and future predicted habitat suitability}

We have formulated a habitat suitability map for the whole study area for 2007, 2017 and 2027, and for the historical study plot for 1955, 1982, 2000 and 2007. In both cases, the average habitat suitability decreased with time (see Fig. 3 for the whole area).

Within the 'historical' study plot, we were forced to apply a simplified logistic model because of the simplified recording of habitat variables, using the following regression equation:

$$
\begin{aligned}
Y= & -3.36+3.13 *(\text { seeded grasslands }+ \text { permanent grasslands } \\
& + \text { permanent grasslands with scattered trees and shrubs }) \\
& -2.52 *(\text { broadleaved woodlands })+3.43 \\
& * \text { (abandoned areas }+ \text { shrublands with trees })
\end{aligned}
$$

However, the simplified and the original model provided nearly identical estimates of predicted probability of occurrence (mean estimate: $0.31 \pm 0.16$ for the original model, $0.30 \pm 0.15$ for the simplified one; $r=0.96, P<0.001$ ); therefore, we can assume that the simplified model could be readily taken as a good substitute for the original one within the historical plot. The average habitat suitability so estimated was equal to $0.65 \pm 0.15$ in 1955 , $0.57 \pm 0.17$ in $1982,0.31 \pm 0.16$ in 2000 and $0.30 \pm 0.15$ in 2007 . Therefore, the current average habitat suitability was less than half what it was in the 1950s.

Table 2

Land-use changes after land abandonment considered for modelling scenarios of habitat suitability. See also Verburg and Overmars (2009), who reported the same sequence of land-use changes.

\begin{tabular}{lll}
\hline Land use: 2007 & Land use: 2017 & Land use: 2027 \\
\hline Seeded grasslands & Abandoned areas & Shrubland with trees \\
Permanent grasslands & Abandoned areas & Shrubland with trees \\
Permanent grasslands with scattered trees and shrubs & Shrubland with trees & Broadleaved woodlands \\
Abandoned areas & Shrubland with trees & Broadleaved woodlands \\
Shrubland with trees & Broadleaved woodlands & Broadleaved woodlands \\
Broadleaved woodlands & Broadleaved woodlands & Broadleaved woodlands \\
\hline
\end{tabular}



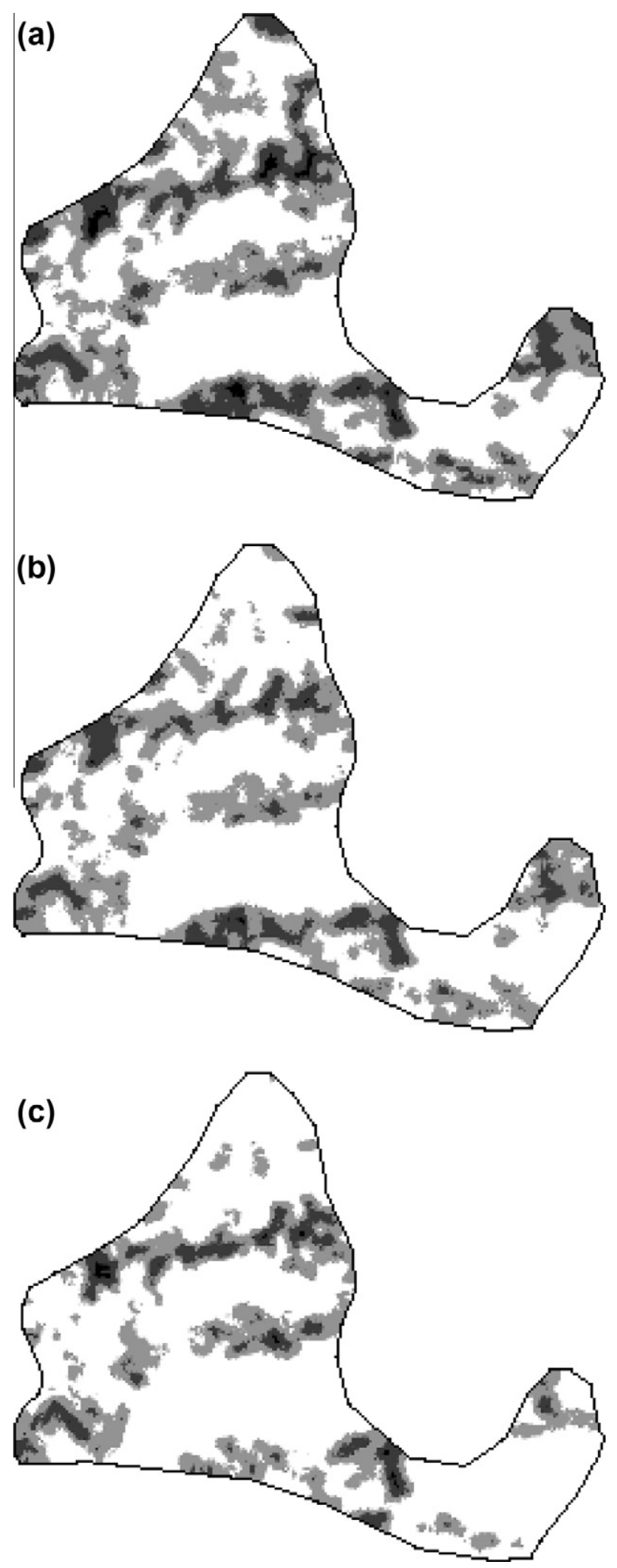

Fig. 3. Habitat suitability map for red-backed shrikes in the study area: (a) 2007; (b) 2017; (c) 2027. Map not displayed for 2037 (no suitable patch left in the area); habitat suitability increases with colour darkness. See text and Table 2 for changes of land-use types during the years and for further information.

Future predictions for abandonment scenarios were even less favourable. A paired sample $t$-test revealed a progressive decrease of habitat suitability (from 2007 to 2017: $t=23.21$; d.f. $=4999$; $P<0.001$; from 2017 to 2027: $t=13.79$; d.f. $=4999 ; P<0.001)$.
For the 2027 prediction, the remaining suitable patches coincided with the original seeded and permanent grasslands, which evolved into shrubland with trees. In the 2037 scenario, there was virtually no suitable patch for red-backed shrikes, because the conversion of open habitats (grassland-like and shrubland) into broadleaved forest will be complete.

Points predicted as occupied in 2007 (mean probability of occurrence $0.74 \pm 0.12$ ) had a mean probability of occurrence of $0.62 \pm 0.22$ in 2017 and $0.50 \pm 0.35$ in 2027 .

The average habitat suitability as predicted by the occurrence probability model decreased from 0.25 in 2007 to 0.21 in 2017 , to 0.17 in 2027, and to 0 in 2037, when the change from shrubland with trees to broadleaved woodlands will end with the consequential disappearance of any remaining semi-open habitats. The number of points predicted as being occupied by red-backed shrikes decreased from 1249 in 2007 to 999 in 2017, (-20.01\%), and to 795 in 2027 (-20.42\% or $-36.35 \%$ since 2007 ) with 0 in 2037.

Under the first partial-abandonment scenario (seeded grasslands maintained and non-seeded grasslands abandoned), the average habitat suitability as predicted by the occurrence probability model decreased from 0.25 (and 1249 points predicted occupancy) in 2007, to 0.23 (1124 'occupied' points) in 2017 and stabilised at around 0.15 in 2027 (686 'occupied' points in 2027, 657 'occupied' points in 2037).

Under the second partial-abandonment scenario (seeded grasslands abandoned, permanent grasslands and permanent grasslands with scattered trees and shrubs maintained), the average habitat suitability as predicted by the occurrence probability model decreased from 0.25 (1249 'occupied' points) in 2007, to 0.22 (1028 'occupied' points) in 2017, to 0.20 (924 'occupied' points) in 2027, and to 0.01 (40 'occupied' points) in 2037.

\section{Discussion}

4.1. Moderate farming creates key habitat resources destroyed by land abandonment

Red-backed shrike territories include a compact mosaic of different habitats (Brambilla et al., 2009a). This is clearly pointed out by the habitat preference model, which indicates the need for both grassland-like habitats and for shrub cover. Fields, permanent grasslands and shrub habitats all have positive effects on the probability of shrike occurrence, while, on the other hand, the only variable negatively affecting shrike occurrence is broadleaved woodland, by far the commonest forest type in the area, which is progressively occupying abandoned areas (Bogliani et al., 2003).

In our sample units (territory and random plots), areas of 'permanent' (i.e. rather stable) shrubland habitats (heathland, montane shrubland, maquis, etc.) do not occur, although they were taken into account for the database we used. All kinds of shrubland found in the sample units within our study area were formed either by shrubs invading recently-abandoned fields or pastures (abandoned areas), or by the first stages of forest expansion over non-forest areas or by the degradation of existing forest habitats (shrubland with scattered trees). These were classed as "areas under evolution" in the DUSAF2 database. The transitory nature of shrubland is well shown by the pattern of land cover in the study plot with historical data (Fig. 2), from which the changeable location of shrub patches is clearly shown.

These findings are consistent with the results of previous studies (Vanhinsbergh and Evans, 2002; Brambilla et al., 2007a; Golawski and Meissner, 2008; Brambilla et al., 2009a) and provide definitive support for the need for 'moderate farming' for shrike conservation in Europe. Low-intensity farming systems, characterised by crop-rotation and short-term land abandonment, allow the 
close coexistence of grass habitats (pastures, hay-meadows and fallows, which are key-foraging places for red-backed shrikes, Golawski and Meissner, 2008), untilled areas and shrubby vegetation which has covered fields left untilled for a few years or which has partly colonized low-grazing pressure pastures (Casale et al., 2007; Casale and Brambilla, 2009).

Moderate farming, which provides a small-scale mosaic of habitats offering different types of resources needed during breeding, all packed together within relatively small areas, includes setaside, fallow land and patches of fields or pastures left untilled for a few years. These increase the abundance and diversity of invertebrates (easily preyed on by shrikes in open habitats) and thus favour shrike occurrence (Casale et al., 2007; Golawski and Meissner, 2008; Brambilla et al., 2009a).

This mix of different habitats, simultaneously required by shrikes, in abandoned areas will be replaced in a few decades by dense tree vegetation, unsuitable for shrikes and many other conservation-priority species, including many species with strongholds in the Apennines (Bogliani et al., 2003; Negri et al., 2005; Brambilla et al., 2007b; Brambilla et al., 2008; Brambilla and Rubolini, 2009; Brambilla et al., 2009b).

\subsection{Trends in habitat suitability: land-use changes generate unfavourable dynamics}

Previous modelling of habitat suitability in dynamic scenarios did not show strong changes in suitability, because of the high stability in land-use projections under a dominant intensive agriculture management (Ficetola et al., 2009). In our study case, land-use has changed significantly in the past 50 years and is likely to change in the future, according to the same trend (Bogliani et al., 2003; Roati, 2007): this change has resulted in a large decline since the 1950s and is predicted to cause a drastic reduction in habitat suitability for shrikes in a land-abandonment scenario, ultimately leading to the complete extinction in the study area (see Section 3).

The availability of historical data about land use and the largely known pattern of recolonization of abandoned fields and grasslands by shrub and trees (Roati, 2007) gave us a unique opportunity for exploring medium-term effects of environmental changes on a declining indicator species. Although such an approach is not so easy to replicate in other contexts (given the large amount and varied type of data required), it provided a powerful assessment of the effects of environmental changes, in our case of the ones associated with human-depopulation of mountainous rural areas and land abandonment, which are an important component of global change. Where available, historical data should be considered for a thorough evaluation of ecological loss or gain which has already occurred and for calibrating future predictions (see also Domenech et al., 2005; Ficetola et al., 2009). Our approach also provided a potentially useful tool for demonstrating to institutions, land managers and the wider public the importance of maintaining traditional farming for biodiversity conservation.

The analyses and maps of predicted habitat suitability further highlight, on the one hand, the negative effect of the land-use changes which are now taking place, and on the other hand the importance of moderate farming for the conservation of farmland biodiversity. A steady decrease in habitat suitability both in terms of mean predicted occurrence and of the extent of suitable areas has been recorded since 1955; average habitat suitability declined by $12 \%$ from 1955 to 1982 , but in 2000 it was reduced to less than half of the historical value (1955). Such a decrease is mainly due to the dramatic reduction of agricultural areas and then of shrubland areas; after a first phase of land abandonment, in 1982 the relatively high extent of shrubland cover (which replaced some of the former grassland areas after abandonment) partly balanced the loss of open habitats; however, land abandonment continued in the following years and by 2000 woodland had spread over wide areas, while both grassland-like habitats and shrublands had declined. On the other hand, other factors not directly tied to landuse could affect the population dynamic of this species (see e.g. Diehl, 1995; Tryjanowski et al., 2006).

The trend shown by a red-backed shrike population in a survey plot located a few kilometres north of our study area is consistent with our scenarios and indirectly confirms the dramatic reduction in habitat suitability from the 1950s to the present as predicted by our modelling exercise. In a study area surveyed since the 1960 s, there were 30 breeding pairs of red-backed shrike in 1963 (Cova, 1965); gradually, the species declined, until it completely disappeared by the end of the last century (C. Cova, pers. comm.). Marked declines of the species in the past $50-60$ years have also been reported for a large portion of the northern Apennines, including our study area (Bogliani et al., 2003).

A further decrease of habitat suitability will take place if land abandonment does not cease (see Section 3 and Fig. 3) and, in the scenario of complete abandonment of agro-pastoral practices, it will probably lead firstly to a drastic reduction of the shrike population within 10-20 years, and then to complete extinction in the study area within 30 years after abandonment. Although such a timeframe is undoubtedly an approximation for the habitat trend, current knowledge about the speed of conversion of agricultural and pastoral areas into denser vegetation types and, ultimately, woodland, suggests that the time needed for a complete cover of forest may be similar (Verburg and Overmars, 2009) or even shorter than the value used in our simulations (Roati, 2007). From our simulations, the decline of habitat suitability is expected to display a stronger effect after 10 20 years: the increase in shrubs and untilled grasslands probably partly compensates for the reduction of open habitats in the first few years after abandonment. This conforms not only to our habitat model (see Section 3), but also to previous studies (Brambilla et al., 2007a) and to habitat association of the species in Italy, where the species is reported to also inhabit abandoned grasslands and shrublands (Arcamone, 1993): all these sources provide evidence for a temporarily limited negative effect of abandonment.

Partial-abandonment scenarios lead to less dramatic declines in habitat suitability. The relative scarcity of both types of permanent grassland habitat (in 2007, the overall area in the 5000 plots was equal to $11 \%$ of the cover of seeded grasslands) resulted in lower benefits ensured by maintenance of grasslands compared to that of seeded grasslands. This occurred despite permanent grasslands (especially those with scattered trees and shrubs, see Section 3) are highly-suitable habitats for shrikes.

Finally, our simulations demonstrate clearly the importance of maintaining suitable low-intensity farming in hilly and mountainous areas of southern Europe.

Whilst other environmental processes may re-create suitable habitat patches, e.g. through fires (Grigulis et al., 2005), they are unlikely to re-build such a suitable landscape mosaic. Adequate policies and targeted subsidies could help the conservation of larger areas of semi-open landscapes shaped by traditional agricultural practices. The results of the analyses involving partialabandonment scenarios suggest that well-targeted subsidies may mitigate the effects of rural abandonment.

\section{Acknowledgments}

We are very grateful to G. Bottari, P. Colombani, G. Ferrario, P. Lenna, A. Martinoli, D. Moreno, F. Piccarolo, F. Picco, S. Ronchi, P. Siccardi, G. Tosi, P. Volonterio for helpful comments and cooperation. Four anonymous reviewers and the editor B. Söderström provided helpful suggestions on a first draft of the ms. N. Sills kindly revised the English text. This study has been funded by FLA and by DGQA of Lombardy Region, and is part of FC's PhD. 


\section{References}

Arcamone, E. 1993. Averla piccola Lanius collurio. In: Meschini, E., Frugis, S. (Eds.), Atlante degli uccelli nidificanti in Italia Suppl Ric Biol Selvaggina, vol. 20. p. 246.

Benton, T.G., Vickery, J.A., Wilson, J.D., 2003. Farmland biodiversity: is habitat heterogeneity the key? Trends in Ecology and Evolution 18, 182-188.

Blondel, J., 2006. The 'design' of Mediterranean landscapes: a millennial story of humans and ecological systems during the historic period. Human Ecology 34, 713-729.

Bogliani, G., Cova, C., Polani, F., 2003. La natura tra Nure e Scrivia. Il territorio del Giardino di Pietra Corva. Provincia di Pavia, Pavia.

Brambilla, M., Guidali, F., Negri, I., 2008. The importance of an agricultural mosaic for Cirl Buntings Emberiza cirlus in Italy. Ibis 150, 628-632.

Brambilla, M., Guidali, F., Negri, I., 2009b. Breeding-season habitat associations of the declining Corn Bunting Emberiza calandra - a potential indicator of the overall bunting richness. Ornis Fennica 86, 41-50.

Brambilla, M., Rubolini, D., 2009. Intra-seasonal changes in distribution and habitat associations of a multi-brooded bird species: implications for conservation planning. Animal Conservation 12, 71-77.

Brambilla, M., Casale, F., Bergero, V., Crovetto, G.M., Falco, R., Negri, I., Siccardi, P., Bogliani, G., 2009a. GIS-models work well, but are not enough: habitat preferences of Lanius collurio at multiple levels and conservation implications. Biological Conservation 142, 2033-2042.

Brambilla, M., Rubolini, D., 2005. Hierarchical partitioning ed ecologia di specie ornitiche. Avocetta 29, 139.

Brambilla, M., Rubolini, D., Guidali, F., 2006. Factors affecting breeding habitat selection in a cliff-nesting peregrine Falco peregrinus population. Journal of Ornithology 147, 428-435.

Brambilla, M., Rubolini, D., Guidali, F., 2007a. Between land abandonment and agricultural intensification: habitat preferences of red-backed shrikes Lanius collurio in low-intensity farming conditions. Bird Study 54, 160-167.

Brambilla, M., Reginato, F., Guidali, F., 2007b. Habitat use by Moltoni's Warbler Sylvia cantillans moltonii in Italy. Ornis Fennica 84, 91-96.

Casale, F., Bionda, R., Falco, R., Siccardi, P., Toninelli, V., Rubolini, D., Brambilla, M. 2007. Misure gestionali in campo agro-pastorale per la conservazione dell'averla piccola Lanius collurio. Atti XIV Convegno Italiano di Ornitologia.

Casale, F., Brambilla, M., 2009. Averla piccola. Ecologia e conservazione. Fondazione Lombardia per l'Ambiente e Regione Lombardia, Milano.

Cevasco, R. 2007. Memoria verde. Nuovi spazi per la geografia. Diabasis, Reggio Emilia.

Chevan, A., Sutherland, M., 1991. Hierarchical partitioning. American Statistician 45, 90-96.

Cova, C., 1965. Ornitologia pratica: come sono, cosa mangiano, quanti sono, dove vivono gli uccelli italiani. Hoepli, Milano.

Debussche, M., Lepart, J., Dervieux, A., 1999. Mediterranean landscape changes: evidence from old postcards. Global Ecology and Biogeography 8, 3-15.

Diehl, B., 1995. A long-term population study of Lanius collurio in a heterogeneous and changing habitat. Proceedings of Western Foundation of Vertebrate Zoology 6, 157-162.

Domenech, R., Vila, M., Pino, J., Gesti, J., 2005. Historical land-use legacy and Cortaderia selloana invasion in the Mediterranean region. Global Change Biology 11, 1054-1064.

Donald, P.F., Pisano, G., Rayment, M.D., Pain, D.J., 2002. The common agricultural policy, EU enlargement and the conservation of Europe's farmland birds. Agriculture, Ecosystems and Environment 89, 167-182.

Farina, A., 1995. Distribution and dynamics of birds in a rural sub-Mediterranean landscape. Landscape and Urban Planning 31, 269-280.

Farina, A., 1997. Landscape structure and breeding bird distribution in a subMediterranean agro-ecosystem. Landscape Ecology 12, 365-378.

Ficetola, G.F., Maiorano, L., Falcucci, A., Dendoncker, N., Boitani, L., Padoa-Schioppa, E., Miaud, C., Thuiller, W., 2009. Knowing the past to predict the future: landuse change and the distribution of invasive bullfrogs. Global Change Biology 16, 528-537.

Fornasari, L., Kurlavicius, P., Massa, R. 1997. Lanius collurio red-backed shrike. In: Hagemeijer, W.J.M., Blair, M.G. (Eds.), The EBCC Atlas of European Breeding Birds. Their Distribution and Abundance. T and AD Poyser, pp. 660-661.

Fouquet, A., Ficetola, G.F., Haigh, A., Gemmell, N., 2010. Using ecological niche modelling to infer past, present and future environmental suitability for Leiopelma hochstetteri, an endangered New Zealand native frog. Biological Conservation $143,1375-1384$

Gibson, L.A., Wilson, B.A., Cahill, D.M., Hill, J., 2004. Spatial prediction of rufous bristlebird habitat in a coastal heathland: a GIS-based approach. Journal of Applied Ecology 41, 213-223.

Gil-Tena, A., Brotons, L., Saura, S., 2009. Mediterranean forest dynamics and forest bird distribution changes in the late 20th century. Global Change Biology 15, 474-485.

Golawski, A., Golawska, S., 2008. Habitat preference in territories of the red-backed shrike Lanius collurio and their food richness in an extensive agriculture landscape. Acta Zoologica Academiae Scientiarum Hungarica 54, 89-97.

Golawski, A., Meissner, W., 2008. The influence of territory characteristics and food supply on the breeding performance of the red-backed shrike (Lanius collurio) in an extensively farmed region of eastern Poland. Ecological Research 23, 347-353.

Grigulis, K., Lavorel, S., Davies, I.D., Dossantos, A., Lloret, F., Vilà, M., 2005. Landscape-scale positive feedbacks between fire and expansion of the large tussock grass, Ampelodesmos mauritanica in Catalan shrublands. Global Change Biology 11, 1042-1053.
Heikkinen, R.K., Luoto, M., Virkkala, R., Rainio, K., 2004. Effects of habitat cover, landscape structure and spatial variables on the abundance of birds in an agricultural-forest mosaic. Journal of Applied Ecology 41, 824-835.

Hromada, M., Antczak, M., Valone, T.J., Tryjanowski, P., 2008. Settling decisions and heterospecific social information use in shrikes. PLOS ONE 3, e3930. doi:10.1371/journal.pone.0003930.

Hurtt, G.C., Frolking, S., Fearon, M.G., et al., 2006. The underpinnings of land-use history: three centuries of global gridded land-use transitions, wood-harvest activity, and resulting secondary lands. Global Change Biology 12, 1208-1229.

Karlsson, S., 2004. Season-dependent diet composition and habitat use of redbacked shrikes Lanius collurio in SW Finland. Ornis Fennica 81, 97-108.

Kuzniak, S., Tryjanowski, P., 2000. Distribution and breeding habitat of the redbacked shrike (Lanius collurio) in an intensively used farmland. Ring 22, 89-93.

Lavorel, S., Canadell, J., Rambal, S., Terradas, J., 1998. Mediterranean terrestrial ecosystems: research priorities on global change effects. Global Ecology \& Biogeography Letters 7, 157-166.

Leemans, R., Zuidema, G., 1995. Evaluating changes in land cover and their importance for global change. Trends in Ecology and Evolution 10, 76-81.

Mac Nally, R., 1996. Hierarchical partitioning as an interpretative tool in multivariate inference. Australian Journal of Ecology 21, 224-228.

Mac Nally, R., 2000. Regression and model-building in conservation biology, biogeography and ecology: the distinction between-and reconciliation of'predictive' and 'explanatory' models. Biodiversity and Conservation 9, 655671.

Maggi, R., 2004. "I munti sun eggi”: the making of the Ligurian landscape in prehistory. In: Balzaretti R, Pearce M, Watkins C., (Eds.), Ligurian Landscapes, Studies in Archaeology, Geography and History, Accordia Specialist Studies on Italy/University of London, London, pp. 71-82.

Mazzoleni, S., di Pasquale, G., Mulligan, M., di Martino, P., Rego, F., 2004. Recent Dynamics of Mediterranean Vegetation and Landscape. John Wiley and Sons Ltd..

Montanari, C., Scipioni, S., Calderoni, G., Leonardi, L., Moreno, D., 2002. Linking anthracology and historical ecology: suggestions from a post-medieval site in the Ligurian Apennines (north-west Italy). British Archaeological Reports International Series, vol. 1063, pp. 235-241.

Moreno, D., Cevasco, R., Guido, M.A., Montanari, C., 2005. L'approccio storicoarcheologico alla copertura vegetale: il contributo dell'archeologia ambientale e dell'ecologia storica. In: Caneva G. (Ed.), La biologia vegetale per i beni culturali, vol. II. "Conoscenza e valorizzazione. Nardini Ed., Firenze, pp. 463-498.

Negri, I., Brambilla, M., Guidali, F., 2005. Abbondanza degli zigoli (Emberizidae) in relazione all'uso del suolo nell'Appennino settentrionale. Avocetta 29, 95.

Ostermann, O.P., 1998. The need for management of nature conservation sites designated under Natura 2000. Journal of Applied Ecology 35, 968-973.

Pearce, J., Ferrier, S., 2000. Evaluating the predictive performance of habitat models developed using logistic regression. Ecological Modelling 133, 225-245.

Peñuelas, J., Filella, I., Comas, P., 2002. Changed plant and animal life cycles from 1952 to 2000 in the Mediterranean region. Global Change Biology 8, 531-544.

Poyatos, R., Latron, J., Llorens, P., 2003. Land use and land cover change after agricultural abandonment - the case of a Mediterranean mountain area (Catalan Pre-Pyrenees). Mountain Research and Development 23, 362-368.

Preiss, E., Martin, J.L., Debussche, M., 1997. Rural depopulation and recent landscape changes in a Mediterranean region: consequences to the breeding avifauna. Landscape Ecology 12, 51-61.

Radford, J.Q., Bennett, A.F., 2004. Thresholds in landscape parameters: occurrence of the white-browed treecreeper Climacteris affinis in Victoria, Australia. Biological Conservation 117, 375-391.

Roati, M. 2007. La dinamica della vegetazione in aree abbandonate dell'Oltrepò pavese. Unpublished PhD Thesis, Università degli Studi di Pavia, Pavia, Italy.

Romero-Calcerrada, R., Perry, G.L.W., 2004. The role of land abandonment in landscape dynamics in the SPA 'Encinares del rio Alberche y Cofio', Central Spain, 1984-1999. Landscape and Urban Planning 66, 217-232.

Rosenzweig, C., Karoly, D., Vicarelli, M., Neofotis, P., Wu, Q., Casassa, G., Menzel, A., Root, T.L., Estrella, N., Seguin, B., Tryjanowski, P., Liu, C., Rawlins, S., Imeson, A., 2008. Attributing physical and biological impacts to anthropogenic climate change. Nature 453, 353-358.

Roura-Pascual, N., Pons, P., Etienne, M., Lambert, B., 2005. Transformation of a rural landscape in the Eastern Pyrenees between 1953 and 2000. Mountain Research and Development 25, 252-261.

Rushton, S.P., Ormerod, S.J., Kerby, G., 2004. New paradigms for modelling species distributions? Journal of Applied Ecology 41, 193-200.

Sala, O.E., Chapin III, F.S., Armesto, J.J., et al., 2000. Global biodiversity scenarios for the year 2100. Science 287, 1770-1774.

Sergio, F., Marchesi, L., Pedrini, P., 2004. Integrating individual habitat choices and regional distribution of a biodiversity indicator and top predator. Journal of Biogeography 31, 619-628.

Sirami, C., Brotons, L., Burfield, I., Fonderflick, J., Martin, J.L., 2008. Is land abandonment having an impact on biodiversity? A meta-analytical approach to bird distribution changes in the north-western Mediterranean. Biological Conservation 141, 450-459.

Sirami, C., Brotons, L., Martin, J.L., 2007. Vegetation and songbird response to land abandonment: from landscape to censusplot. Diversity and Distributions 13, $42-52$.

Suárez-Seoane, S., Osborne, P.E., Baudry, J., 2002. Responses of birds of different biogeographic origins and habitat requirements to agricultural land abandonment in northern Spain. Biological Conservation 105, 333-344. 
Thomas, C.D., Cameron, A., Green, R.E., et al., 2004. Extinction risk from climate change. Nature 427, 145-148.

Tryjanowski, P., Golawski, A., 2004. Sex differences in nest defence by the redbacked shrike Lanius collurio: effects of offspring age, brood size, and stage of breeding season. Journal of Ethology 22, 13-16.

Tryjanowski, P., Golawski, A., Kuzniak, S., Mokwa, T., Antczak, M., 2007. Disperse or stay? Exceptionally high breeding-site infidelity in the red-backed shrike Lanius collurio. Ardea 95, 316-320.

Tryjanowski, P., Sparks, H.T., Crick, H.Q.P., 2006. Red-backed shrike Lanius collurio nest performance in a declining British population: a comparison with a stable population in Poland. Ornis Fennica 83, 181-186.
Tucker, G.M., Evans, M.I., 1997. Habitats for Birds in Europe: A Conservation Strategy for the Wider Environment. Birdlife International, Cambridge, UK.

Vanhinsbergh, D., Evans, A., 2002. Habitat associations of the red-backed shrike (Lanius collurio) in Carinthia, Austria. Journal of Ornithology 143, 405415.

Verburg, P.H., Overmars, K.P., 2009. Combining top-down and bottom-up dynamics in land use modeling: exploring the future of abandoned farmlands in Europe with the Dyna-CLUE model. Landscape Ecology 24, 1167-1181.

Walsh, C., Mac Nally, R., 2003. Hierarchical Partitioning. R Project for Statistical Computing. <http://cran.r-project.org/> 